\title{
Evaluating the effectiveness and cost- effectiveness of the Smoking Treatment Optimisation in Pharmacies (STOP) intervention: protocol for a cluster randomised controlled trial
}

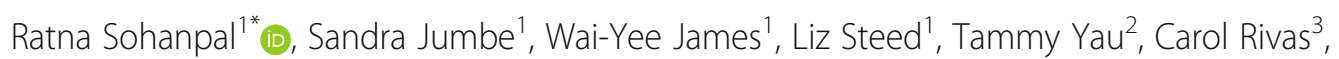
Vichithranie Madurasinghe ${ }^{1}$, Colin Houlihan', Vlad Berdunisov', Matthew Taylor ${ }^{4}$, Stephanie J. C. Taylor ${ }^{1}$, Chris Griffiths ${ }^{1}$, Sandra Eldridge ${ }^{1}$ and Robert Walton ${ }^{1}$

\begin{abstract}
Background: NHS community pharmacies provide effective smoking cessation services; however, there is scope for increasing throughput and improving quit rates. This trial examines whether the Smoking Treatment Optimisation in Pharmacies (STOP) intervention can improve smoker engagement to increase service throughput, retention and quitting.

Methods: This study is a pragmatic, cluster randomised controlled trial in 60 pharmacies in England and Wales. All workers in intervention pharmacies are offered STOP training while control pharmacies provide usual care. The STOP intervention, based on behavioural and organisational theories, comprises educational sessions for staff and environmental prompts in the pharmacy. Intervention fidelity is assessed by actors visiting pharmacies posing as smokers. The primary outcome is throughput, defined as the number of smokers who join the programme, set a firm quit date and undergo at least one stop smoking treatment session, and is measured using routinely collected data. Secondary outcomes include retention and quit rates at 4 weeks and continuous abstinence at 6 months verified by salivary cotinine. Cost-effectiveness is estimated using quality-adjusted life years and the probability that the intervention is effective at different levels of willingness to pay is calculated.
\end{abstract}

Discussion: The trial will generate evidence to inform the public health smoking cessation strategy in England and Wales, and may help to shape service commissioning decisions. The STOP intervention model may help inform the undertaking of a range of health behaviour change tasks in community pharmacies.

Trial registration: ClinicalTrials.gov, ISRCTN16351033. Retrospectively registered on 21 March 2017.

Keywords: Smoking cessation, Community pharmacy, Recruitment, Retention, Behaviour change, Cluster randomised controlled trial, Quit rate

\footnotetext{
* Correspondence: r.sohanpal@qmul.ac.uk

${ }^{1}$ Centre for Primary Care and Public Health, Blizard Institute, Barts and The

London School of Medicine and Dentistry, Queen Mary University of London,

London, UK

Full list of author information is available at the end of the article
}

(c) The Author(s). 2019 Open Access This article is distributed under the terms of the Creative Commons Attribution 4.0 International License (http://creativecommons.org/licenses/by/4.0/), which permits unrestricted use, distribution, and reproduction in any medium, provided you give appropriate credit to the original author(s) and the source, provide a link to the Creative Commons license, and indicate if changes were made. The Creative Commons Public Domain Dedication waiver (http://creativecommons.org/publicdomain/zero/1.0/) applies to the data made available in this article, unless otherwise stated. 


\section{Background}

The tobacco epidemic is one of the biggest public health threats the world has ever faced, killing more than 7 million people each year [1]. Although the smoking prevalence has decreased recently in the United Kingdom, 19\% of adults still smoke [2], which is a similar proportion to that observed in other developed countries [2]. A total of 1.7 million UK hospital admissions were recorded for conditions attributed to smoking in 2014/15 (22\% more hospital admissions than in 2004/05). Thus, tobacco use has considerable negative implications for the individual, society and the National Health Service [2].

UK national guidance [3] stipulates that all health professionals should ask people if they smoke and give brief advice on smoking cessation, offering referral to the NHS Stop Smoking Service if appropriate. The Stop Smoking Service provides evidence-based treatment comprising intensive behavioural support (one-to-one or group), and discussion of medication options by personnel trained according to the National Centre for Smoking Cessation and Training (NCSCT) standard $[4,5]$.

A recent systematic review [6] suggested that community pharmacy-delivered interventions for smoking cessation ( $n=14$ studies) can be effective and cost-effective. However, the number of people using NHS Stop Smoking Services in community pharmacies has declined in recent years [6,7] and there is evidence to suggest that participating pharmacies may target only smokers perceived as likely to quit $[4,7]$. Retention of smokers within the service is poor, with about one-third of those setting a quit date being lost to follow up $[4,8]$.

There are no trials specifically focused on approaches to improve uptake and retention in the NHS community pharmacy smoking cessation service. Increasing throughput in this service may increase the numbers of people successfully giving up smoking, thus helping to reduce the burden of morbidity and mortality from tobacco use.

The protocol for this study has been written following the SPIRIT guidance [9] (see Additional file 1 for the populated SPIRIT checklist).

\section{Study aims}

The primary aim of the Smoking Treatment Optimisation in Pharmacies (STOP) trial is to assess the effectiveness of a new training and service optimisation intervention (referred to as the STOP intervention) [10] on smoker throughput, retention and quit rates in the community pharmacy NHS Stop Smoking Programme.

The secondary aims are to assess cost-effectiveness and willingness to pay, smoker cessation, service user satisfaction with the stop smoking programme and pharmacy staff self-efficacy in delivery of stop smoking advice, and to conduct a process evaluation to evaluate fidelity of implementation, clarify causal mechanisms and identify factors associated with variation in outcomes [11].

\section{Intervention and comparator Intervention group}

The intervention community pharmacies are offered the STOP intervention, a service optimisation and behavioural skills training programme which is theory-driven and developed following the MRC recommendations for complex interventions [11] using a behaviour change framework [12] and embedded theory (social cognitive, self-determination) [13, 14]. We used a realist review of smoking cessation interventions in pharmacies [15] and diffusion of innovations theory [16] to plan optimal implementation.

Detailed descriptions of the development of the STOP intervention, including strategies to achieve the intended aims [4, 8, 10], acceptability and feasibility [17], and methods for assessing intervention fidelity are published elsewhere [18].

\section{Control group}

Community pharmacies in the control group continue with their usual practice; that is, delivery of the NHS Stop Smoking Programme according to the NCSCT programme $[19,20]$.

\section{Aims of the STOP intervention}

The STOP intervention is targeted at all community pharmacy staff (including counter assistants as well as pharmacists) and aims to:

(i) increase throughput of smokers into the Stop Smoking Programme by building up communication skills and cessation knowledge of frontline community pharmacy staff (e.g. counter assistants); and

(ii) increase retention in the Programme and improve quit rates by building up consultation skills and knowledge about smoking cessation in stop smoking advisors.

\section{Methods}

\section{Trial design}

A pragmatic, cluster randomised controlled trial was performed with community pharmacies as the unit of randomisation. Pharmacies are allocated to the STOP training intervention or usual care (control group) using stratified randomisation with a 1:1 ratio.

The flowchart of the STOP trial is illustrated in Fig. 1.

Figure 2 shows a PRagmatic Explanatory Continuum Indicator Summary (PRECIS)-2 diagram [21] of the STOP trial at the smoker participant level. Each axis represents one of nine domains measuring how closely 


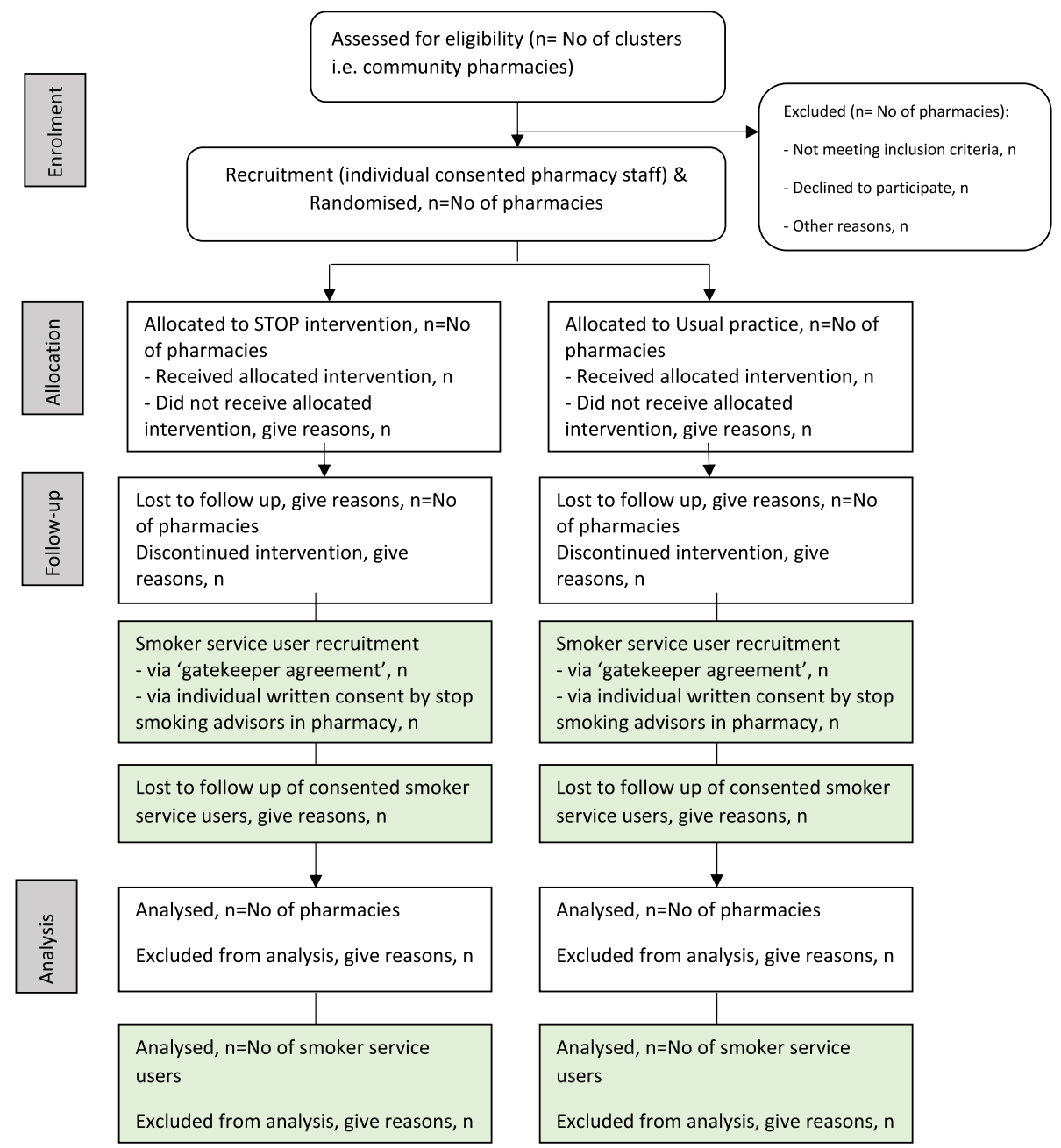

Fig. 1 Flow diagram of progress of clusters and individuals through phases of the trial. STOP Smoking Treatment Optimisation in Pharmacies

the trial is related to real life, scored from $1=$ very explanatory to $5=$ very pragmatic. Pragmatic trials are undertaken in the real world under usual care conditions and the results are intended to support a decision to deliver the intervention in routine practice [22]. The STOP trial is at the pragmatic end of the pragmatic-explanatory continuum.

\section{Setting}

Sixty community pharmacies in London and Coventry, England and Cwn Taf, south east Wales.

\section{Sample size}

The expected mean recruitment in a control cluster over the 11 months of the study is 165 (based on pilot/feasibility data) [17]. We consider that an increase of $33 \%$ in the intervention clusters to 220 would be sufficient to change commissioning policy. The standard deviation of throughput is expected to be approximately 63 in both groups, based on historical data from a service commissioner in the pilot/feasibility study and local authority data [23]. To have $90 \%$ power to detect this difference at the $5 \%$ significance level we need 56 clusters. We have added two clusters to each arm to allow for drop out, increasing the number of community pharmacies required to 60 .

In order to assess quit rates, written individual consent is sought by advisors trained in the research processes (see Recruitment of smoker service users). Service users who join the Stop Smoking Programme over the continuous 11-month period are offered the opportunity to participate, with the aim of recruiting approximately 20 service users per pharmacy.

\section{Recruitment and randomisation of community pharmacies}

Recruitment of community pharmacies and pharmacy workers

Eligible community pharmacies are those providing the NHS Stop Smoking Programme and are identified from 


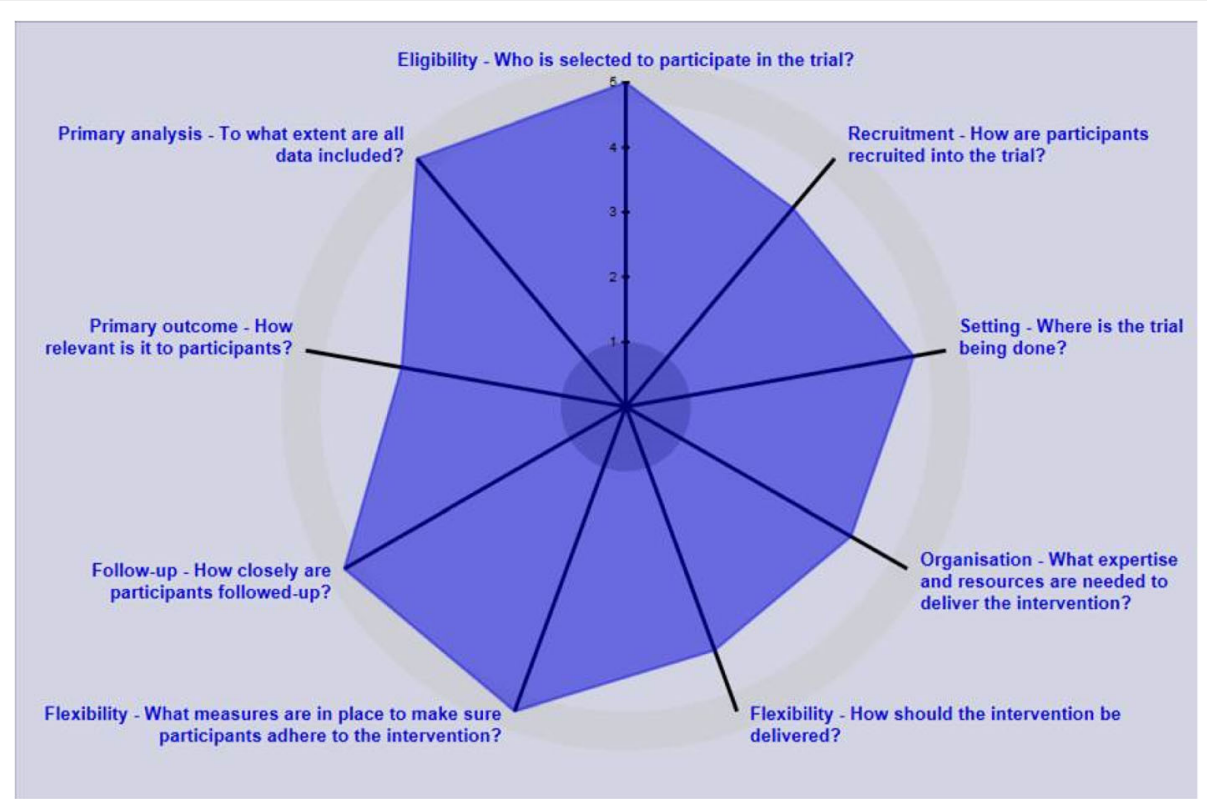

Fig. 2 PRECIS-2 diagram illustrating that the trial lies towards the pragmatic end of the pragmatic-explanatory continuum. The Smoking Treatment Optimisation in Pharmacies trial was scored for each of nine domains from $1=$ very explanatory to $5=$ very pragmatic in group discussion with trialists and methodologists, and the results are displayed as a radar diagram [21]. PRECIS PRagmatic Explanatory Continuum Indicator Summary

lists provided by service commissioners. Figure 3 gives an overview of the complex organisational structure of community pharmacies in England. The pharmacy owner is approached with an invitation letter or email, with an enclosed participant information sheet, and then followed up with a phone call after a few days. A meeting is then scheduled with the lead pharmacist and their staff (both stop smoking advisors and support or counter assistants) to discuss the study in detail and obtain written informed consent for participation. Following receipt of written consent, pharmacy characteristics (e.g. whether the pharmacy is a chain or independent) and pharmacy staff demographics are collected.

\section{Randomisation}

The community pharmacies are randomised to the STOP training intervention or to usual practice (no training) in a 1:1 ratio with stratified block randomisation for the pharmacy commissioner and number of prescriptions dispensed per month per pharmacy (as a proxy for pharmacy footfall), using an online system to ensure allocation concealment.

To reduce contamination due to staff crossover in small-chain pharmacies, a pharmacy chain where the owner has fewer than five pharmacies is randomised as one unit. For large pharmacy chains (owner has more than five pharmacies, e.g. Boots, Superdrug), individual outlets are randomised; each outlet is a separate randomising unit. The owners of large pharmacy chains or the head office confirmed to the study team at recruitment that there would be no staff crossover to the study team, and this was confirmed during trial monitoring visits.

The study team recruiting pharmacies emails an independent statistician with details of consented pharmacies for allocation. The independent statistician then performs the randomisation and notifies the study team of pharmacy allocation by email.

\section{Blinding}

The smoker service users are blind to the pharmacy's allocation. Pharmacy staff are not blind to the intervention allocation; however, the collection of primary outcome data is via routine data collection, so the chances of bias are minimised. Follow-up assessments are conducted by a team not blind to the experimental intervention; however, validation of the reported smoking status is by salivary cotinine test performed by ABS Laboratories, which is blind to allocation.

\section{Participants}

In this study there are two types of participants in relation to study outcomes and data collection (Table 2):

(1) Pharmacy staff, including stop smoking advisors and support staff (related to process outcomes).

(2) Service users in participating pharmacies (following 'gatekeeper agreement' [25]). The service users eligible for inclusion are self-reported current 


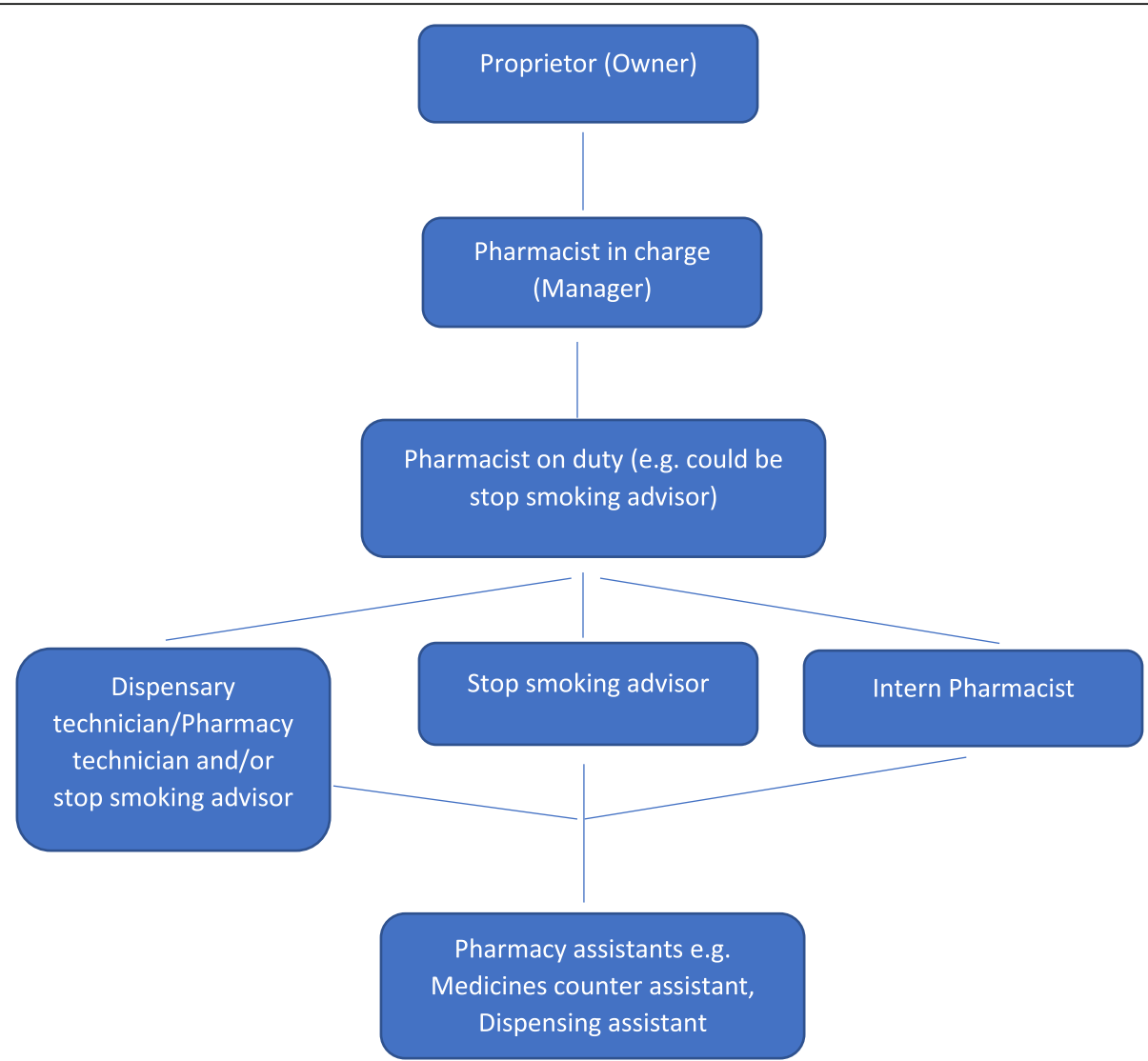

Fig. 3 Illustration of the organisational structure of community pharmacies in England [24]. Proprietor (owner): if owns five or less community pharmacies, pharmacy is referred to as independent; if owns more than five community pharmacies, pharmacy is referred to as chain

smokers aged 18 years and older who join the Stop Smoking Programme and attend the first stop smoking session (related to the primary outcome).

(2a)A subgroup of service users who give individual, written, informed consent for additional data collection procedures (related to secondary outcomes).

\section{Recruitment of smoker service users}

All service users who join the NHS Stop Smoking Service in participating pharmacies are considered part of the trial. Recruitment of service users, consenting for additional data collection, takes place over an 11-month period beginning immediately following the staff training session in intervention pharmacies and 1 month after the site initiation visit in control pharmacies (Table 2).

Stop smoking advisors in all participating pharmacies undergo research-related training to take written informed consent and collect saliva samples from consenting service users. All service users who attend the first stop smoking session of the NHS Stop Smoking
Programme (routine visit 1) are approached by their stop smoking advisor at the end of the session to participate in additional data collection procedures (Table 2) using a study information sheet and consent form. Written consent is taken from those interested within $24 \mathrm{~h}$ or at the next appointment in the pharmacy. This time period was found to be a convenient and acceptable way to consent service users in the feasibility study [17] and was approved by the ethics committee. Figure 4 illustrates the process of recruitment.

\section{Retention strategies}

To maximise retention of pharmacies, pharmacy staff and service commissioners, we applied evidence-based strategies [26] and findings from our feasibility study [17].

A service contracting agreement is made with each participating pharmacy that includes the list/protocol of research-related work to be carried out. Training is provided in research-specific procedures and monitoring visits are planned to ensure the advisors carry out the research activities listed in the service contract. Good communication and relationships are maintained throughout between pharmacy staff and the study research team by regular contact using WhatsApp closed 


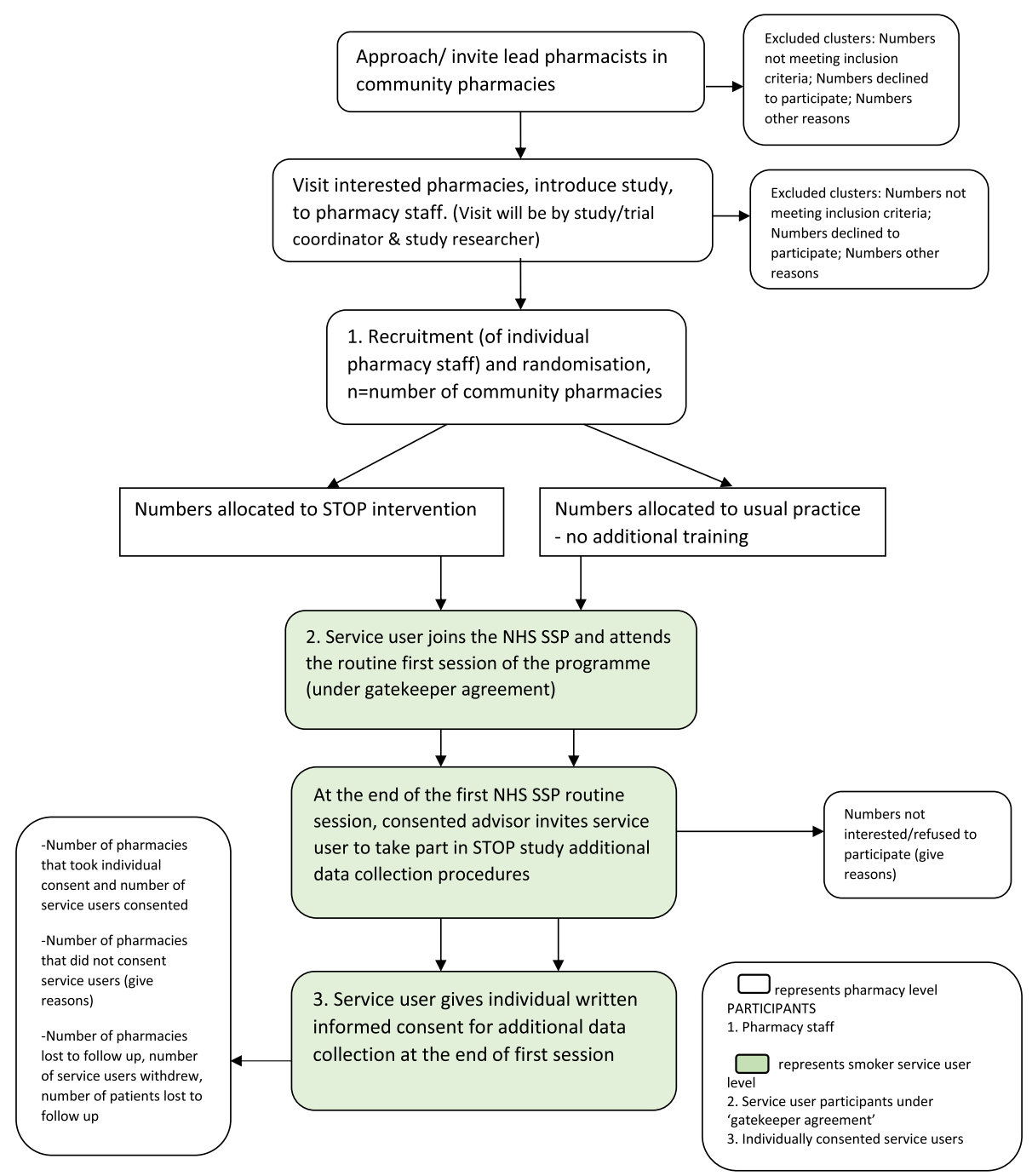

Fig. 4 Process of recruitment. NHS SSP, National Health Service Stop Smoking Programme, STOP Smoking Treatment Optimisation in Pharmacies

groups, email and phone calls. WhatsApp messages giving study information are sent to separately created control and intervention groups.

Pharmacy staff receive a $£ 10$ voucher for returning saliva samples to the study team and service users receive a $£ 5$ voucher for returning the satisfaction questionnaires. Service commissioners receive reimbursement for the time taken to send routine smoking cessation data to the study team at $£ 40 / \mathrm{h}$. STOP intervention training is incentivised by providing $£ 40$ in cash for counter assistants to attend one training session and $£ 80$ for pharmacists/stop smoking advisors to cover payment for attending two training sessions, including and travel expenses. Payments are based on hourly rates following discussion with the local Clinical Research Network (NOCLOR Research Support Service) that supports researchers in the set-up and conduct of research in primary care/community clinical settings. A 'certificate of completion' is given to each staff member for attending and completing the training.

\section{Data collection and measurements Baseline characteristics}

The pharmacy information and staff demographics are presented in Table 1, and service user demographics are presented in Table 2.

\section{Primary outcome}

The primary outcome measure is throughput assessed using routinely collected data supplied by service commissioners and defined as the number of smokers who:

1. join the stop smoking programme;

2. set a firm quit date; and 
Table 1 Baseline demographics

\begin{tabular}{lll}
\hline Baseline demographics & \\
\hline Pharmacy information & $\begin{array}{l}\text { Contractor code, type of pharmacy (independent/chain), total number of staff } \\
\text { (both full-time and part-time), number of stop smoking advisors, number of } \\
\text { pharmacy support staff. The study team also obtain the number of prescriptions } \\
\text { dispensed monthly for each participating pharmacy from the Pharmacy and }\end{array}$ & $\begin{array}{l}\text { Directly from consented } \\
\text { pharmacist/advisor }\end{array}$ \\
& $\begin{array}{l}\text { Appliance Contractor Dispensing data report } \\
\text { (publicly available) [23] }\end{array}$ & At baseline Directly from consented \\
Pharmacy staff & Job title, highest education level, age, gender, smoking status & support staff \\
& &
\end{tabular}

3. undergo at least one consultation on or prior to the quit date (i.e. a 'treated smoker' according to the Russell standard [28]).

\section{Secondary outcomes}

Using the Russell Standard criteria [28], we assess the following:

- The 4-week retention rate-the proportion of treated smokers retained at 4 weeks. A treated smoker is counted as 'lost to follow up at 4-weeks' (LFU4W) if, on attempting to determine the 4-week quit status, she/he cannot be contacted. The national guidance [29] recommends that pharmacy staff determine the quit status at 4 weeks in at least $85 \%$ of cases but there is no guidance given on the number of attempts allowed to follow up service users. Hence, the number of attempts and process of follow up used by staff may vary between pharmacies [17].

- The 4-week quit rate-the proportion of smokers who quit smoking at 4 weeks from the set quit date (i.e. a 'carbon monoxide (CO)-verified 4-week quitter').

In addition, continuous abstinence assessment of individually consented smokers-defined as the proportion of smokers who quit at 4 weeks (CO-verified) and remained so at 6 months (ascertained by telephone interview and verified by salivary cotinine) - is determined together with factors that may influence quit rates (e.g. gender, ethnicity).

Table 2 describes the type of data collected (i.e. trial outcome data, process data including intervention fidelity and tissue data), the source of data and the time point of collection.

The SPIRIT figure (Fig. 5) provides information on the study visits and the activities/assessments at each visit.

\section{Economic evaluation}

A cost-effectiveness analysis comparing the STOP intervention to usual care is conducted from the perspective of the NHS and personal social services. The cost of delivering the intervention to participants (e.g. training of pharmacy advisors and additional time spent consulting service users) is obtained by the study team and valued using published sources of UK costs [29, 30].

The intervention cost is combined with lifetime cost and quality-adjusted life years (QALYs) gained, estimated using a previously published economic model for analysis of smoking cessation and relapse [31]. A Markov cohort simulation predicts the likely smoking status and, subsequently, the health status of a cohort of 1000 hypothetical patients, each receiving a specific treatment strategy. The model accounts for various smoking-related morbidities, each associated with a cost and an impact upon the patient's quality of life. Mortality rates are also included, for smokers and former smokers, and survival, combined with quality of life inputs, is used to generate expected QALYs.

The cost-effectiveness model uses the 6-month quit rate from the trial as the measure of short-term efficacy of the intervention. The long-term quit rate is unknown and is likely to be an important source of uncertainty, but is calculated using a combination of the 6-month quit rate, medium-term relapse rates and long-term 'natural background' quit rates, the latter two derived from the published literature. Background quit rates and the probability of relapse obtained from the literature simulate the proportion of the cohort who remain abstinent in future years.

One-way sensitivity analyses test the robustness of the model to assumptions of long-term effectiveness. A probabilistic sensitivity analysis gauges the combined effect of uncertainty around all model parameters simultaneously. The probability of cost-effectiveness of the intervention assuming different levels of willingness to pay per QALY is illustrated using a cost-effectiveness acceptability plane.

\section{Data management and analysis}

Data are stored in the Queen Mary University of London (trial sponsor) secure virtualised environment with dual-factor authentication. A full statistical analysis plan is developed prior to release of allocation codes to anyone involved in writing that plan. We compare the numbers of participants enrolled in the Stop Smoking 


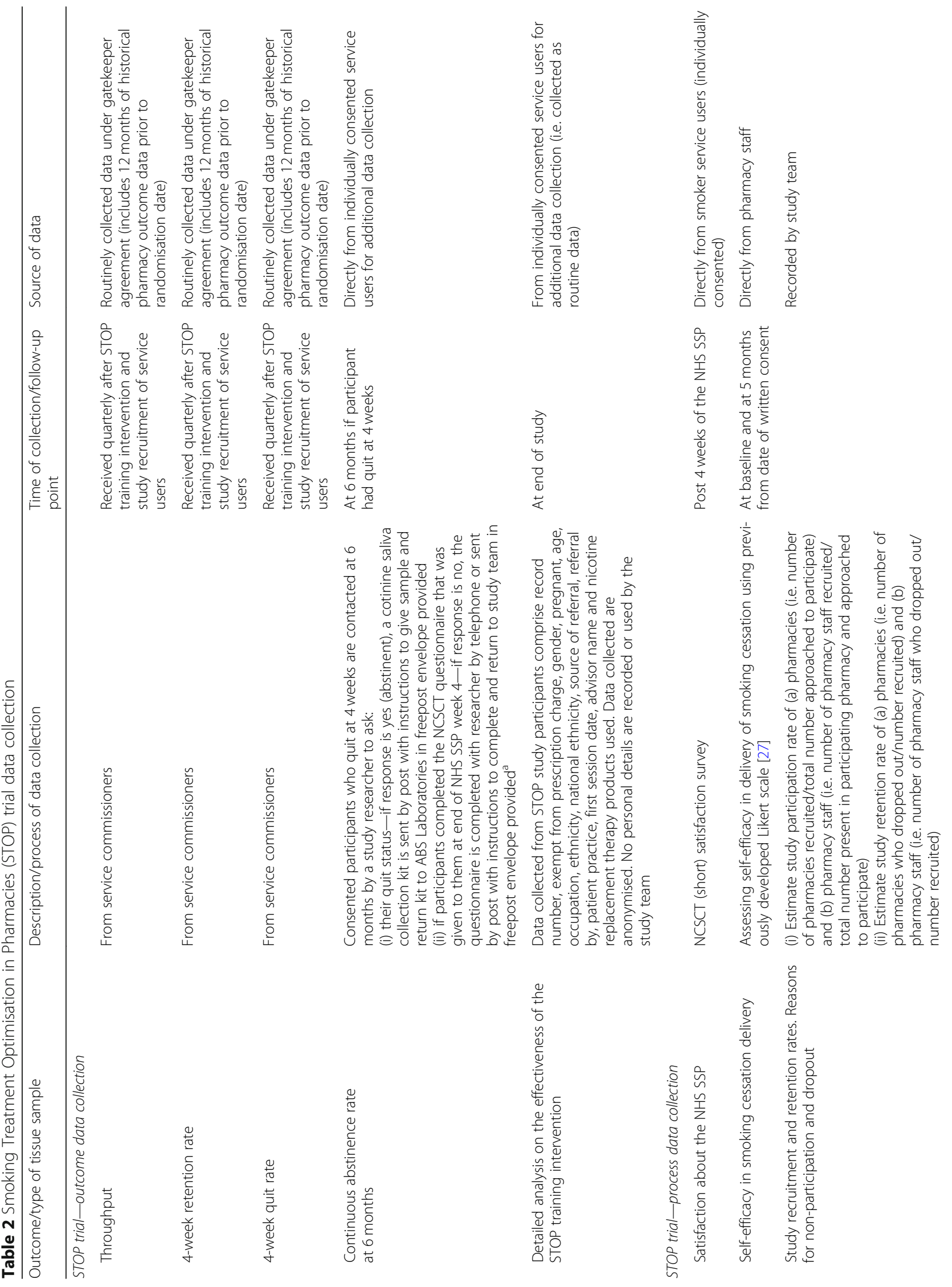




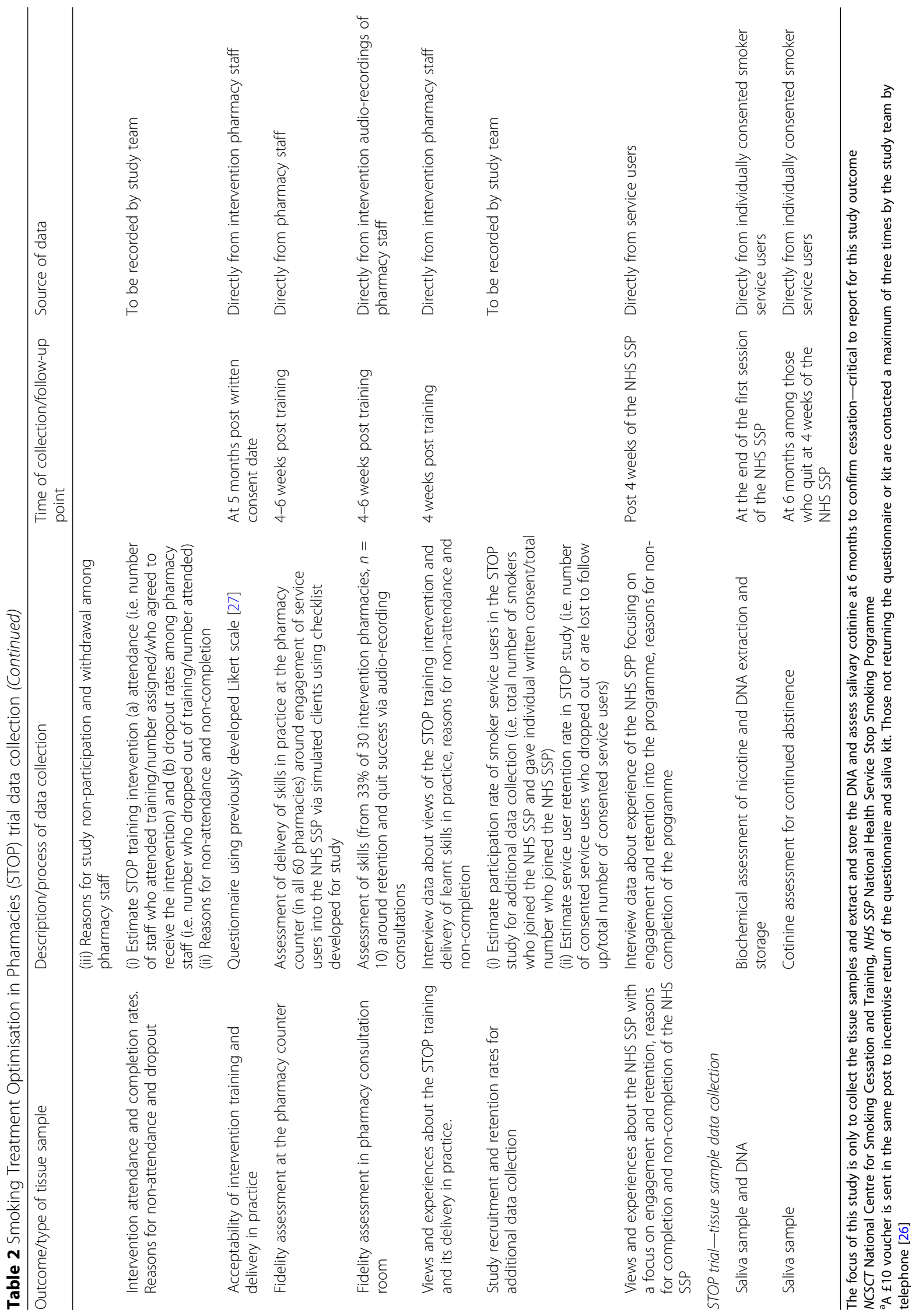




\begin{tabular}{|c|c|c|c|c|c|c|c|c|}
\hline \multicolumn{2}{|l|}{ Visit / Activity / Assessment } & $\begin{array}{l}\text { 1) Study } \\
\text { visit - } \\
\text { pre-study, } \\
\text { recruitment } \\
\text { and } \\
\text { baseline } \\
\text { assessment } \\
\text { in pharmacy }\end{array}$ & \begin{tabular}{|l|} 
2) Study visit - \\
Advisor \\
training in \\
study \\
procedures e.g. \\
GCP, service \\
user \\
recruitment, \\
saliva sample \\
collection
\end{tabular} & $\begin{array}{l}\text { 3) Study } \\
\text { activity- } \\
\text { STOP training } \\
\text { intervention } \\
\text { allocated to } \\
\text { pharmacies in } \\
\text { intervention } \\
\text { group in/out } \\
\text { of pharmacy }\end{array}$ & $\begin{array}{l}\text { 4) Study } \\
\text { visit - } \\
\text { assessment } \\
\text { in pharmacy } \\
\text { 4-6weeks } \\
\text { post } \\
\text { training }\end{array}$ & \begin{tabular}{|l|} 
5) Study visit \\
- individual \\
interview \\
with \\
pharmacy \\
staff in \\
pharmacy 4 \\
weeks post \\
training
\end{tabular} & $\begin{array}{l}\text { 6) Study visit } \\
\text {-follow up } \\
\text { data } \\
\text { assessment } 5 \\
\text { months post } \\
\text { consent date } \\
\text { in pharmacy }\end{array}$ & $\begin{array}{l}\text { 7) Study } \\
\text { visit - End of } \\
\text { service user } \\
\text { recruitment } \\
\text { - collect } \\
\text { health } \\
\text { economic/c } \\
\text { ost data } \\
\text { (study site } \\
\text { close-up) }\end{array}$ \\
\hline \multicolumn{2}{|c|}{$\begin{array}{l}\text { Study team obtains written informed consent from } \\
\text { pharmacist (also a stop smoking advisor), other stop } \\
\text { smoking advisor/s and pharmacy support staff }\end{array}$} & $\mathrm{x}$ & & & & & & \\
\hline & & \multicolumn{7}{|c|}{ From individual consented pharmacy staff } \\
\hline \multicolumn{2}{|l|}{ All staff complete demographics questionnaire } & $\mathrm{x}$ & & & & & & \\
\hline \multicolumn{2}{|l|}{$\begin{array}{l}\text { All staff complete pre-training self-efficacy } \\
\text { questionnaire }\end{array}$} & $\mathrm{x}$ & & & & & & \\
\hline \multicolumn{2}{|c|}{$\begin{array}{l}\text { Advisor training in study procedures e.g. GCP, service } \\
\text { user recruitment, saliva sample }\end{array}$} & & $x$ & & & & & \\
\hline \multicolumn{2}{|l|}{$\begin{array}{l}\text { All staff in intervention pharmacies attend STOP } \\
\text { training }\end{array}$} & & & $x$ & & & & \\
\hline \multicolumn{2}{|l|}{$\begin{array}{l}\text { Fidelity assessment of engagement behaviour of } \\
\text { pharmacy staff at pharmacy counter }\end{array}$} & & & & $\mathrm{x}$ & & & \\
\hline \multicolumn{2}{|c|}{$\begin{array}{l}\text { Fidelity assessment of retention behaviour of advisors } \\
\text { in pharmacy consultation room }\end{array}$} & & & & $\mathrm{x}$ & & & \\
\hline \multicolumn{2}{|c|}{$\begin{array}{l}\text { Intervention staff complete acceptability of training } \\
\text { questionnaire }\end{array}$} & & & & & & $\mathrm{x}$ & \\
\hline \multicolumn{2}{|c|}{ Staff complete post-training self-efficacy questionnaire } & & & & & & $\mathrm{x}$ & \\
\hline \multicolumn{2}{|c|}{ Intervention staff take part in face-to-face interview } & & & & & $\mathrm{x}$ & & \\
\hline \multicolumn{2}{|c|}{$\begin{array}{l}\text { Study researcher to collect health economic data and } \\
\text { close site. }\end{array}$} & & & & & & & $\mathrm{x}$ \\
\hline Visit / Activity /Assessment & \multicolumn{5}{|c|}{$\begin{array}{l}\text { Routine treatment visits/sessions of a smoker service user who joins } \\
\text { and attends the NHS SSP }\end{array}$} & \multicolumn{3}{|c|}{ Study visits } \\
\hline \multirow[t]{2}{*}{ Visit / Activity /Assessment } & \multicolumn{3}{|c|}{ NHS SSP first routine session (week 1) } & $\begin{array}{l}\text { NHS SSP } \\
\text { second } \\
\text { routine } \\
\text { session (1-2 } \\
\text { weeks + 7 } \\
\text { days) }\end{array}$ & \begin{tabular}{l|} 
NHS SSP \\
last \\
routine \\
session \\
(week \\
$4+14$ days \\
CO- \\
verified \\
quitter)
\end{tabular} & $\begin{array}{l}\text { Service user is } \\
\text { interviewed by } \\
\text { study interviewer } \\
\text { in pharmacy post } \\
\text { week 4) }\end{array}$ & \multicolumn{2}{|c|}{$\begin{array}{l}\text { Follow up of service } \\
\text { users who quit at } 4 \\
\text { weeks of NHS SSP at } 6 \\
\text { months by phone to ask } \\
\text { quit status. If yes, ask to } \\
\text { give saliva sample. } \\
\text { Service user also asked if } \\
\text { completed NCSCT } \\
\text { questionnaire, if not, ask } \\
\text { to complete. }\end{array}$} \\
\hline & $\begin{array}{l}\text { Service } \\
\text { the sess }\end{array}$ & $\begin{array}{l}\text { user attends } \\
\text { ion/ week } 1\end{array}$ & $\begin{array}{l}\text { At end of session } \\
\text { of week } 1\end{array}$ & & & & & \\
\hline $\begin{array}{l}\text { Service user in STOP study under } \\
\text { 'gatekeeper agreement' }\end{array}$ & & $\mathrm{x}$ & & & & & & \\
\hline $\begin{array}{l}\text { Advisor introduces and explains the STOP } \\
\text { study, hands out information sheet }\end{array}$ & & & $\mathrm{x}$ & & & & & \\
\hline \multirow{2}{*}{$\begin{array}{l}\text { Advisor obtains written informed consent for } \\
\text { study additional data collection }\end{array}$} & & & $x$ & & & & & \\
\hline & \multicolumn{6}{|c|}{ From individual consented service users in STOP study } & & \\
\hline $\begin{array}{l}\text { Service user gives one saliva sample for DNA } \\
\text { (using kit)a - Advisor to post to host Centre } \\
\text { CPCPH. } \\
\text { One saliva sample (using kit)b for assessment } \\
\text { of nicotine metabolic profile (using 3-OH } \\
\text { cotinine). Advisor to post to ABS labs via } \\
\text { freepost. }\end{array}$ & & & $x$ & & & & & \\
\hline $\begin{array}{l}\text { Service user consents to sharing their } \\
\text { routinely collected NHS SSP data with study } \\
\text { team }\end{array}$ & & & $x$ & & & & & \\
\hline $\begin{array}{l}\text { Service user completes NCSCT (short) } \\
\text { satisfaction questionnaire and returns it via } \\
\text { freepost to study team or completes } \\
\text { questionnaire at } 6 \text { months over the phone } \\
\text { with researcher. }\end{array}$ & & & & & $x$ & & & $\mathrm{x}$ \\
\hline $\begin{array}{l}\text { Service user takes part in face-to-face } \\
\text { interview about experience of NHS SSP }\end{array}$ & & & & & & $x$ & & \\
\hline $\begin{array}{l}\text { Service user gives one saliva sample (using } \\
\text { kit) to assess cotinine for continued } \\
\text { abstinence and return sample to ABS labs via } \\
\text { freepost. }\end{array}$ & & & & & & & & $\mathrm{x}$ \\
\hline
\end{tabular}

Fig. 5 Standard Protocol Items: Recommendations for Interventional Trials (SPIRIT) figure. CO carbon monoxide, GCP Good Clinical Practice, NCSCT National Centre for Smoking Cessation and Training, NHS SSP, National Health Service Stop Smoking Programme, STOP Smoking Treatment Optimisation in Pharmacies 
Programme between pharmacies allocated to the STOP training intervention and those who are not, using a mixed-effects Poisson regression model with the pharmacy as the random effect to allow for clustering. The dependent variable will be the number of 'treated smokers' from each pharmacy. The model will include two stratification factors-the commissioning site and the number of prescriptions/forms per month. Other covariates to be included in the model will be agreed a priori before the analysis plan is signed off.

\section{Discussion}

This is the first randomised controlled trial to assess the effectiveness and cost-effectiveness of an intervention designed to optimise smoker throughput and retention in the NHS Stop Smoking Programme. The systematic, theory-based development and iterative refinement of the intervention before evaluation in the main trial is a strength of the study $[10,18]$.

As this is a multi-site trial in different parts of the United Kingdom, and is taking place in the setting where patients already receive their usual care, the likelihood that the findings can be generalised is increased. The intervention has potential to be modified to support other public health interventions with health behaviour or clinical outcomes delivered in community pharmacies.

The study is translational in nature with direct implications for health service provision in NHS community pharmacies and provides essential data to assess the cost-effectiveness of the intervention, thus informing commissioning decisions [32].

\section{Trial status}

The trial is ongoing as protocol version 4, dated 21 March 2017. The recruitment period for pharmacies was from 1 June 2017 to 1 March 2018 and for smoker participants was from 1 June 2017 to 1 January 2019.

\section{Additional file}

Additional file 1: SPIRIT 2013 checklist: recommended items to address in a clinical trial protocol and related documents (DOC $122 \mathrm{~kb}$ )

\section{Acknowledgements}

This study was funded by the NIHR Programme Grants for Applied Research (PGfAR) (reference RP-PG-0609-10181). The views expressed are those of the author(s) and not necessarily those of the NHS, the NIHR or the Department of Health.

The authors are grateful to Professor Trish Greenhalgh and Dr Natalia Hounsome for their helpful comments on drafts of the manuscript.

\section{Availability of data and materials}

Not applicable.

\section{Authors' contributions}

RW is Chief Investigator and CG, SE, SJCT, TG and MT are co-investigators. RS wrote the trial protocol and drafted the paper with input from all authors. LS led development of the initial version of the intervention with input from CR and RS. SJ and W-YJ repiloted the intervention with VM and designed the final version. VM evaluated the pilot trial and provided recommendations for the main trial protocol. W-YJ, SJ, TY and CH recruited the sites. SJ and W-YJ delivered the trial intervention. MT developed the economic model and VB arranged collection of economic data. All authors read and approved the final manuscript

\section{Ethics approval and consent to participate}

Ethical approval was obtained for the study from South Central-Hampshire A Research Ethics Committee; REC reference 17/SC/0067 given on 3 Apri 2017. Individual informed consent will be obtained from pharmacy staff participants and smoker service users for additional data collection.

\section{Consent for publication}

Not applicable.

\section{Competing interests}

The authors declare that they have no competing interests.

\section{Publisher's Note}

Springer Nature remains neutral with regard to jurisdictional claims in published maps and institutional affiliations.

\section{Author details}

${ }^{1}$ Centre for Primary Care and Public Health, Blizard Institute, Barts and The London School of Medicine and Dentistry, Queen Mary University of London, London, UK. ${ }^{2}$ California Northstate University, 9700 West Taron Drive, Elk Grove, CA 95757, USA. ${ }^{3}$ Institute of Education, University College London, London, UK. ${ }^{4}$ York Health Economics Consortium, University of York, York, UK.

Received: 8 October 2018 Accepted: 15 April 2019

Published online: 10 June 2019

\section{References}

1. Tobacco. http://www.who.int/mediacentre/factsheets/fs339/en/. Accessed 15 Sept 2018

2. Statistics on Smoking, England. 2016. http://digital.nhs.uk/catalogue/ PUB20781. Accessed 15 Sept 2018.

3. National Institute for Health and Care Excellence: Smoking: brief interventions and referrals. Public health guideline. 2006. https://www.nice. org.uk/guidance/ph1. Accessed 15 Sept 2018.

4. Sohanpal R, Rivas C, Steed L, MacNeill V, Kuan V, Edwards E, Griffiths C, Eldridge S, Taylor S, Walton R. Understanding recruitment and retention in the NHS community pharmacy stop smoking service: perceptions of smoking cessation advisers. BMJ Open. 2016;6:7.

5. National Institute for Health and Care Excellence: NICE support for commissioning for smoking cessation: supporting people to stop smoking. 2013. https://www.nice.org.uk/guidance/qs43/resources/support-forcommissioning-for-smoking-cessation-supporting-people-to-stop-smokingpdf-253672525. Accessed 15 Sept 2018.

6. Brown TJ, Todd A, O'Malley CL, Moore HJ, Husband AK, Bambra C, Kasim A, Sniehotta FF, Steed L, Summerbell CD. Community pharmacy interventions for public health priorities: a systematic review of community pharmacydelivered smoking, alcohol and weight management interventions. Public Health Res. 2016:4:2

7. Statistics on NHS Stop Smoking Services in England-April 2014 to March 2015. https://webarchive.nationalarchives.gov.uk/20180307182643/http:// digital.nhs.uk/catalogue/PUB18002. Accessed 15 Sept 2018.

8. Rivas C, Sohanpal R, MacNeill V, Steed L, Edwards E, Antao L, Griffiths C, Eldridge S, Taylor S, Walton R. Determining counselling communication strategies associated with successful quits in the National Health Service community pharmacy Stop Smoking programme in East London: a focused ethnography using recorded consultations. BMJ Open. 2017;7:10.

9. Chan A-W, Tetzlaff JM, Gøtzsche PC, Altman DG, Mann H, Berlin JA, Dickersin K, Hróbjartsson A, Schulz KF, Parulekar WR, et al. SPIRIT 2013 explanation and elaboration: guidance for protocols of clinical trials. BMJ. 2013;346:e7586

10. Steed $L$, Sohanpal $R$, James $W-Y$, Rivas $C$, Jumbe $S$, Chater A, Todd A, Edwards E, Macneil V, Macfarlane F, et al. Equipping community pharmacy 
workers as agents for health behaviour change: developing and testing a theory-based smoking cessation intervention. BMJ Open. 2017;7:8.

11. Medical Research Council. Developing and evaluating complex interventions: a new quidance. London: Medical Research Council; 2008

12. Michie $S$, van Stralen MM, West R. The behaviour change wheel: a new method for characterising and designing behaviour change interventions. Implement Sci. 2011;6:42.

13. Ryan RM, Deci EL. Self-determination theory and the facilitation of intrinsic motivation, social development, and well-being. Am Psychol. 2000;55(Suppl 1):68-78.

14. Bandura A. Self-efficacy: toward a unifying theory of behavioral change. Psychol Rev. 1977;84(Suppl 2):191-215.

15. Greenhalgh T, Macfarlane F, Steed L, Walton R. What works for whom in pharmacist-led smoking cessation support: realist review. BMC Med. 2016; 14(Suppl 1):209.

16. Greenhalgh T, Robert G, Macfarlane F, Bate P, Kyriakidou O. Diffusion of innovations in service organizations: systematic review and recommendations. Milbank Q. 2004;82(Suppl 4):581-629.

17. Madurasinghe WW, Sohanpal R, James W, Steed L, Eldridge S, Taylor S, Griffiths C, Walton R. Smoking Treatment Optimisation in Pharmacies (STOP): a cluster randomised pilot trial of a training intervention. Pilot Feasibility Stud. 2017;3(Suppl 1):1.

18. Jumbe S, James WY, Madurasinghe V, Steed L, Sohanpal R, Yau TK, Taylor, S, Eldridge S, Griffiths C, Walton R. Evaluating NHS Stop Smoking Service engagement in community pharmacy using simulated smokers: fidelity assessment of a theory-based intervention. BMJ Open. 2019;9:e026841.

19. West R, McEwen A, Lorencatto F, Michie S, Churchill S, Willis N. In: McEwen A, editor. NCSCT Training Standard. Dorchester: Learning Outcomes for Training of Stop Smoking Practitioners: National Centre for Smoking Cessation and Training; 2013.

20. NCSCT. National Centre for Smoking Cessation and Training. http://www. ncsct.co.uk/pub_training.php. Accessed 15 Sept 2018.

21. Forbes G, Loudon K, Treweek S, Taylor SJC, Eldridge S. Understanding the applicability of results from primary care trials: lessons learned from applying PRECIS-2. J Clin Epidemiol. 2017;90:119-26.

22. Loudon $K$, Treweek $S$, Sullivan F, Donnan P, Thorpe KE, Zwarenstein M. The PRECIS-2 tool: designing trials that are fit for purpose. BMJ. 2015;350:h2147.

23. Dispensing contractors' data. https://www.nhsbsa.nhs.uk/prescription-data/ dispensing-data/dispensing-contractors-data. Acccessed 15 Sept 2018.

24. About community pharmacy. http://psnc.org.uk/psncs-work/aboutcommunity-pharmacy/. Accessed 15 Sept 2018.

25. Taljaard M, Weijer C, Grimshaw JM, Eccles MP. The Ottawa Statement on the ethical design and conduct of cluster randomised trials: précis for researchers and research ethics committees. BMJ. 2013. https://doi.org/10. 1136/bmj.f2838.

26. Brueton VC, Tierney JF, Stenning S, Meredith S, Harding S, Nazareth I, Rait G, Strategies to improve retention in randomised trials: a Cochrane systematic review and meta-analysis. BMJ Open. 2014. https:/doi.org/10.1136/ bmjopen-2013-003821.

27. Brose $L S$, West R, Michie S, McEwen A. Evaluation of face-to-face courses in behavioural support for stop smoking practitioners. J Smok Cessat. 2012;7 Suppl 01:25-30.

28. West R, Hajek P, Stead L, Stapleton J. Outcome criteria in smoking cessation trials: proposal for a common standard. Addiction. 2005;100(Suppl 33):299-303.

29. NHS Employers. Pharmacy-based stop smoking services: optimising commissioning. In: NHS Employers. 2009. https://www.nhsemployers.org/ / media/Employers/Publications/Smoking_Cessation_Guidance_fb230709.pdf. Accessed 15 Sept 2018.

30. Curtis LA, Burns A. Unit Costs of Health and Social Care 2016. Personal Social Services Resarch Unit, University of Kent, Canterbury.

31. Taylor M, Leonardi-Bee J, Agboola S, McNeill A, Coleman T. Cost effectiveness of interventions to reduce relapse to smoking following smoking cessation. Addiction. 2011;106(Suppl 10):1819-26.

32. Decommissioning of locally commissioned services. PSNC Guidance for LPCs. http://psnc.org.uk/services-commissioning/locally-commissionedservices/decommissioning-of-locally-commissioned-services/. Accessed 15 Sept 2018.

\section{Ready to submit your research? Choose BMC and benefit from:}

- fast, convenient online submission

- thorough peer review by experienced researchers in your field

- rapid publication on acceptance

- support for research data, including large and complex data types

- gold Open Access which fosters wider collaboration and increased citations

- maximum visibility for your research: over $100 \mathrm{M}$ website views per year

At BMC, research is always in progress.

Learn more biomedcentral.com/submissions 